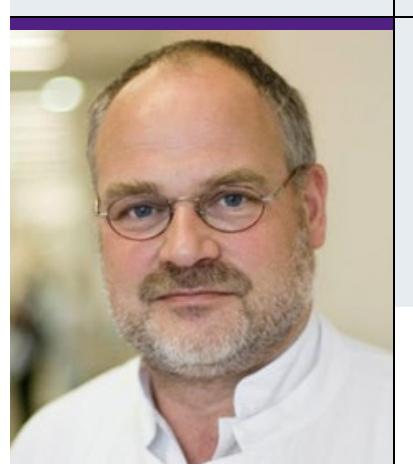

„Die Länder mit der höchsten Mütter- und Kinder-

sterblichkeit liegen in Krisenregionen von Krieg,

zerfallenden Staaten und Terrorregimen. Und von

dort wollen die Menschen nur noch weg."

Prof. Dr. med. Ekkehard Schleußner

ist Direktor der Klinik für Frauenheilkunde und Geburtshilfe Abteilung Geburtshilfe am Universitätsklinikum Jena

\title{
Millennium Goal und Flüchtlinge - wie reimt sich das?
}

V or genau 15 Jahren trafen sich die Staats- und Regierungschefs der Vereinten Nationen zur großen 55. Generalversammlung (MillenniumGipfel) in New York. Dort verabschiedeten die 189 Mitgliedsstaaten einen Maßnahmenkatalog mit konkreten Zielvorgaben und dem übergeordneten Vorsatz, die Armut in der Welt bis 2015 zu halbieren (Millennium Goals). Vertreter der Vereinten Nationen, der Weltbank, des IWF und vom Entwicklungsausschuss der OECD erarbeiteten vier Handlungsfelder: 1. Frieden, Sicherheit und Abrüstung; 2. Entwicklung und Armutsbekämpfung, 3. Schutz der gemeinsamen Umwelt, 4. Menschenrechte, Demokratie und gute Regierungsführung. Daraus abgeleitet wurden acht konkrete Ziele für 2015 formuliert:

- Bekämpfung von extremer Armut und Hunger

_Primärschulbildung für alle

_ Gleichstellung der Geschlechter/Stärkung der Rolle der Frauen

- Senkung der Kindersterblichkeit

- Verbesserung der Gesundheitsversorgung der Mütter

- Bekämpfung von HIV/AIDS, Malaria und anderen schweren Krankheiten

_Ökologische Nachhaltigkeit

_ Aufbau einer globalen Partnerschaft für Entwicklung.

Für uns Frauenärzte sind besonders Ziele 4 und 5 bedeutsam, betreffen sie doch den Kern unseres Berufs.

Im August wurde der Millennium Development Goals Report 2015 veröffentlicht. Jedoch - die Ziele wurden verfehlt! Die Müttersterblichkeit sank global um $45 \%$, ein beachtlicher Erfolg, doch es waren $75 \%$ angestrebt. Und es gibt große Unterschiede: Während in Ostasien eine Senkung um 65\% gelang, erreichten die Karibik-Staaten nur 36\%. In den entwickelten Ländern sank die Müttersterblichkeit von 26 auf 16 pro 100.000 Lebendgeburten (außer USA mit 22/100.000).

Die Kindersterblichkeit sank weltweit um $53 \%$ statt um die anvisierten zwei Drittel. In den entwickelten Ländern wurde eine Reduktion von 61 \% erreicht, in
Ostasien $71 \%$, während in der Sub-Sahara-Region noch immer jedes 11. Kind vor dem 5. Geburtstag stirbt. Die Resultate dürfen nicht kleingeredet werden. Vielmehr können wir dankbar sein für die mit großen internationalen Anstrengungen erreichten Erfolge. Vielleicht sind diese aber auch geringer als in den Statistiken genannt. Ursachen für die Müttersterblichkeit z. B. sind nur zur Hälfte bekannt (in entwickelten Ländern zu 75\%). Und wer glaubt ernsthaft, dass jemand in Somalia, Libyen, Irak oder Syrien die Totgeburten oder die bei der Geburt gestorbenen Mütter zählt?

Bleibt die Frage, warum die vereinbarten Ziele verfehlt wurden. Damals schien eine erfolgreichere globale Entwicklung möglich - die Ost-West-Konfrontation war vorbei, das westliche Demokratiemodell und entsprechende Wirtschaftskonzepte weltweit erfolgreich. Ein Jahr später stürzte mit den Twin Towers diese offenbare Illusion zusammen. Unsummen von finanziellen und humanen Ressourcen wurden nun nicht mehr in Entwicklung, sondern in Terrorabwehr gesteckt. Die Schwerpunkte von Politik und Gesellschaft veränderten sich nachhaltig. Die Länder mit der höchsten Mütter- und Kindersterblichkeit liegen in Krisenregionen von Krieg, zerfallenden Staaten und Terrorregimen. Und von dort wollen die Menschen nur noch weg - ich würde das auch wollen. Heute stehen sie vor unseren Türen als Flüchtlinge.

Wir sind alle gefordert, das Notwendige, das Menschliche zu tun, unserem ärztlichen Ethos gerecht zu werden und mit unserer ärztlichen Kunst zu helfen. Eine Lösung kann aber nur gelingen, wenn Krieg gebannt wird, Lebensperspektiven für alle Menschen in ihrer Heimat bestehen - und Mütter wie Kinder nicht an häufig leicht vermeidbaren Ursachen sterben.

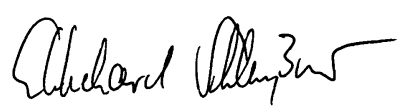

